\title{
Compare features of human dental pulp cells cultured from pulp tissues with and without cryopreservation
}

\author{
Ming Yan, Ola A. Nada, Ralf Smeets, Martin Gosau, Reinhard E. Friedrich, Lan Kluwe
}

\begin{abstract}
Background and Aims. Teeth extracted are usually disposed as bio-waste whereas they could serve as an autologous tissue for culturing multipotent dental pulp cells which have application potential in regenerative medicine. This study aimed to examine the feasibility of cryopreserving dental pulp tissue at teeth extraction for later culturing of cells.

Methods. The pulp tissue from each of a total of 10 teeth was cut into small fragments which were then divided into two portions. One portion was directly used for culturing pulp cells using the explant method. The other portion was cryopreserved with $10 \%$ DMSO in liquid nitrogen for at least one month and then thawed for culturing pulp cells.

Results. Vital cells were obtained from all the 10 pulp fragment suspensions which went through cryopreservation. The cell outgrowth from the explants of cryopreserved pulp fragments was two days later than that of corresponding fresh pulp tissue. Otherwise, no difference was observed in proliferation, expression of stem cell markers and differentiation into adipose cells and osteoblasts between the two groups of cells cultured from the fresh or the cryopreserved pulp fragments.
\end{abstract}

Conclusions. Cryopreserving fragmented dental pulp tissue provides a feasible option for saving pulp tissues as autologous cell sources for possible later application.

Key words: dental pulp cells, differentiation, dental pulp tissue, cell culture, tissue cryopreservation, osteogenic differentiation, adipogenic differentiation

Received: May 6, 2020; Revised: September 25, 2020; Accepted: November 27, 2020; Available online: December 15, 2020 https://doi.org/10.5507/bp.2020.061

(c) 2021 The Authors; https://creativecommons.org/licenses/by/4.0/

${ }^{a}$ Department of Oral and Maxillofacial Surgery, University Medical Center Hamburg-Eppendorf, Hamburg 20246, Germany Corresponding author: Lan Kluwe, e-mail: kluwe@uke.de

\section{BACKGROUND}

Dental pulp cells exhibit features of stem cells and therefore provide a valuable cell source for tissue engineering and regeneration medicine ${ }^{1}$.These cells can be obtained from wisdom teeth and any other teeth which are extracted for medical indications ${ }^{2,3}$. For the patients, cells derived from their own teeth are autologous which will not cause host rejection in potential later application ${ }^{4}$. Dental pulp cells are vital, grow fast, are easy to handle in culture and exhibit high potential in multiple lineage differentiation especially into the osteogenic, adipogenic and condrogenic lineages 5 . With their neural crest origin, dental pulp cells exhibit higher neurogenic differentiation potential than bone marrow mesenchymal stem cells and therefore may be especially valuable for neuro-regeneration ${ }^{6}$.

Cultured dental pulp cells can be cryopreserved for the long term and used for studies and applications at a later time ${ }^{7}$. However, conventional cryopreservation with $10 \%$ dimethyl sulfoxide (DMSO) is usually applied for single cells cultured in laboratories ${ }^{8}$. To obtain such single cells, the resources required are demanding and only available at limited hospitals and clinics. Though many people will likely have some of their teeth extracted during their life, teeth are disposed of as waste whereas they could provide a valuable autologous source for these patients for possible future application.
To solve this problem and to enable culturing pulp cells for more patients, cryopreservation of dental pulp tissues at surgery may provide a strategy. Indeed, cryopreservation has been shown to be feasible for storing adipose tissues for more than 6 weeks from which vital cells can be successfully cultured later ${ }^{9}$. Because the pulp tissues contain hardly any connecting tissues and the cells are loosely packed, we hypothesized that cryopreservation may be applied to dental pulp tissues without damaging large numbers of cells. When the pulp tissue is cut into small fragments, the cryo-protecting agent DMSO penetrates the tissues well and enters the cells as is the case of a single cell suspension. The present study is designed to test our hypothesis and to examine the feasibility of cryopreserving pulp tissues at the site of teeth extraction. Paired fresh pulp tissue and cryopreserved ones were used for culturing pulp cells in an identical experimental setting. Outgrowth from the tissue explants, morphology, proliferation, expression of stem cell markers and differentiation potential of the cells derived from the two difference sources were compared.

\section{METHODS}

\section{Specimen}

A total of 10 wisdom teeth of healthy donors were collected. According to the local regulation for privacy 


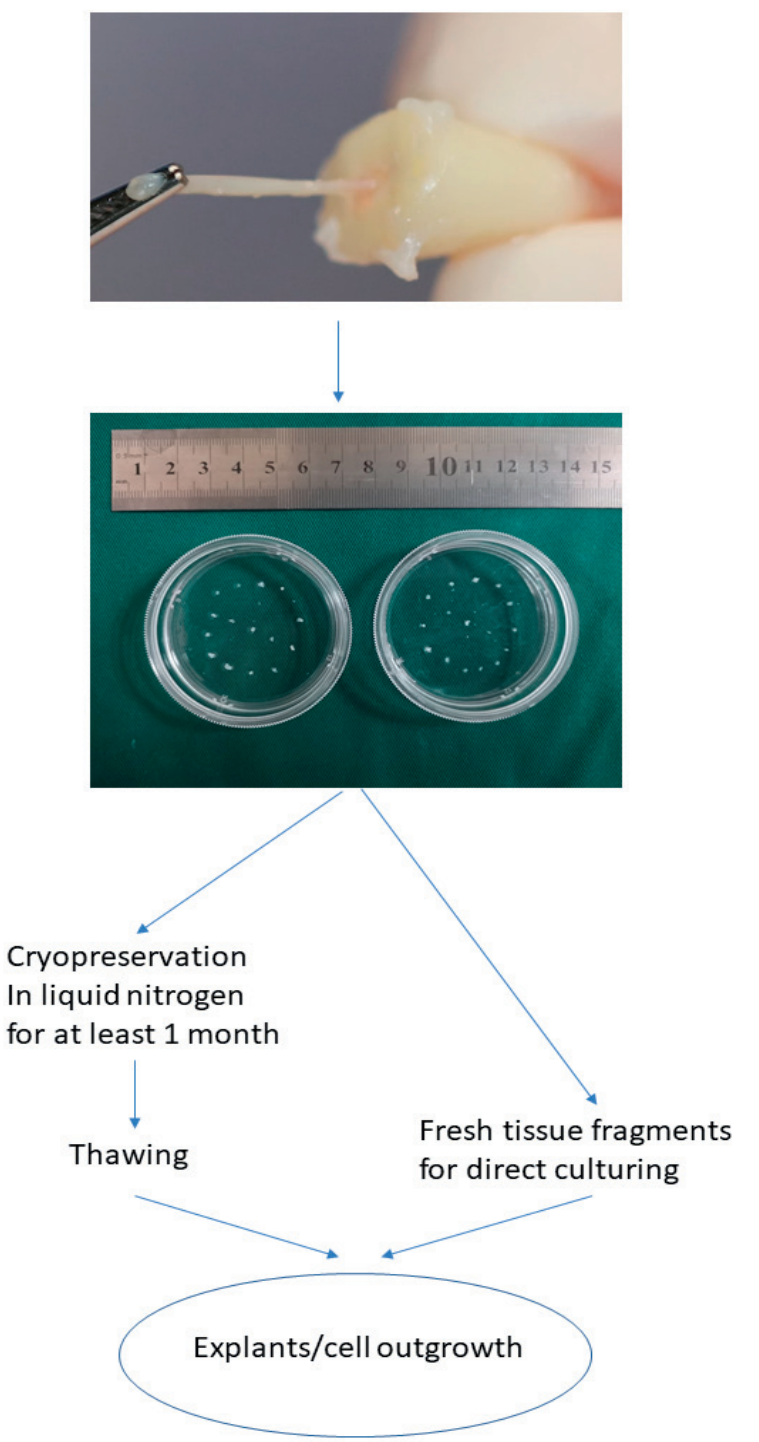

Fig. 1. An illustration of the procedure. A dental pulp pulled out from a tooth was cut into small fragments in medium. The fragment suspension was divided into two parts, one as fresh tissue for immediate culturing and the other for cryopreservation which was thawed later and used for culturing.

protection, all specimens used for the study were anonymized. Patients signed the informed consent for the scientific use of teeth. Patients were instructed to gargle with a $1 \%$ hydrogen peroxide solution before the tooth extraction. The surgeon conducted a routine disinfection around the mouth. After the extraction, the teeth were kept in a Dulbecco's phosphate-buffered saline (DPBS) solution supplemented with $2 \times 10^{5} \mathrm{U} / \mathrm{L}$ penicillin and streptomycin at $4^{\circ} \mathrm{C}$ medium for up to 4 hours.

\section{Cryopreservation of the pulp tissue fragments}

Each tooth was rinsed with DPBS solution several times before it was broken with a hammer. The pulp tissue was pulled out with a tweezer and immersed into DMEM in culture dish where it was cut into small pieces of ap-
A
Cryopreserved group

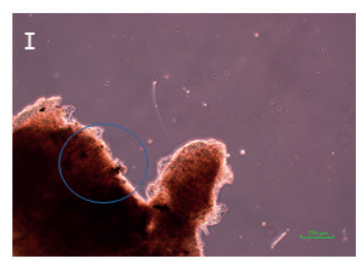

Day 7

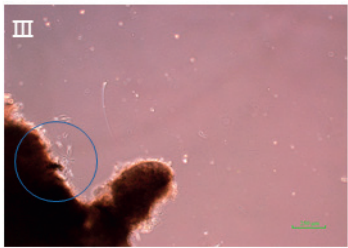

Day 7 Enlarged

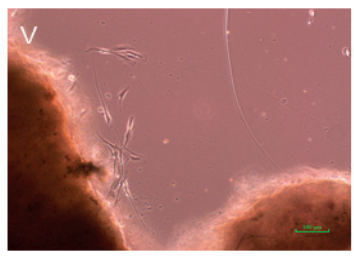

Day 4

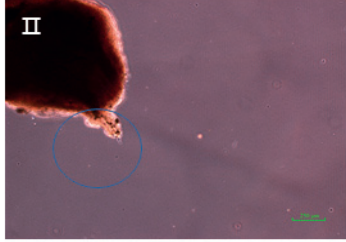

Day 5

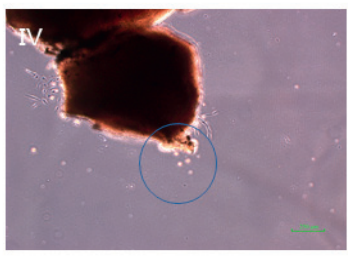

Day 5

Enlarged

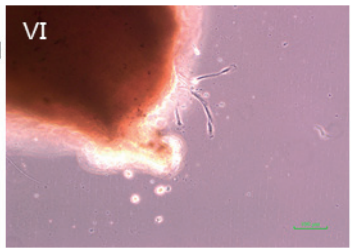

Immediate culturing group

B

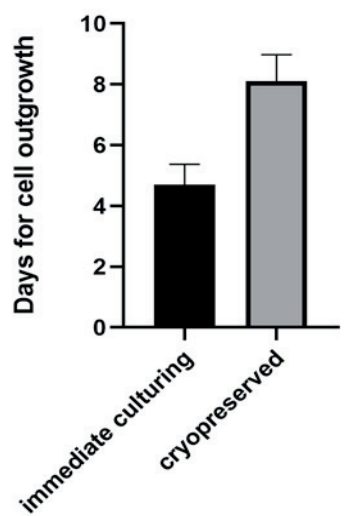

Fig. 2. A. Cell outgrowth from paired cryopreserved and immediate culturing groups. For cryopreserved group, cell growing out of the explants were visible in the circled area on day 7 (A-III). Note that no cells were visible one day before day 6 (A-I) in the same circled area. For immediate culturing group, cell outgrowth started two-day earlier, on day 5 (A-IV). B. Cell outgrowth for the 10 paired cryopreserved and fresh pulp fragments in mean and standard deviation.

proximately $0.5 \mathrm{~mm}^{3}$ (Fig. 1). The pulp tissue fragments were divided into 2 parts: one as fresh pulp tissue for immediate culturing and the other part for cryopreservation (Fig. 1). Cryopreservation was carried out by adding (DMSO) to a final concentration of $10 \%$, cooling down the $1.6 \mathrm{~mL}$ suspension in a $4^{\circ} \mathrm{C}$ refrigerator for 1 hour, slowly freezing to $-80^{\circ} \mathrm{C}$ overnight in a freezing container and finally storing in liquid nitrogen for at least six weeks.

\section{Thawing the cryo-preserved tissue fragments and culturing cells}

The tube containing the $1.6 \mathrm{ml}$ cryopreserved suspension of the pulp tissue fragments was removed from the liquid nitrogen and immediately placed in a water bath of $37^{\circ} \mathrm{C}$. The cells were thawed within one minute and 

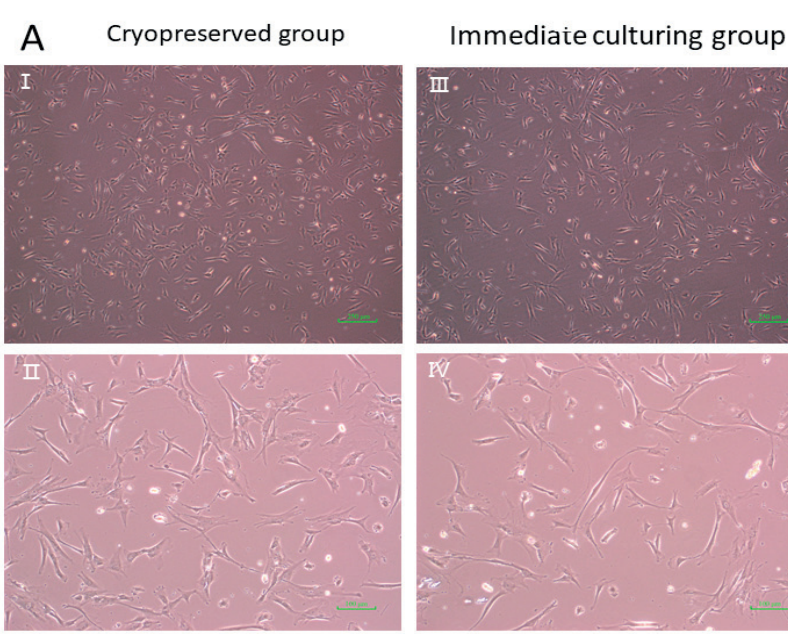

B

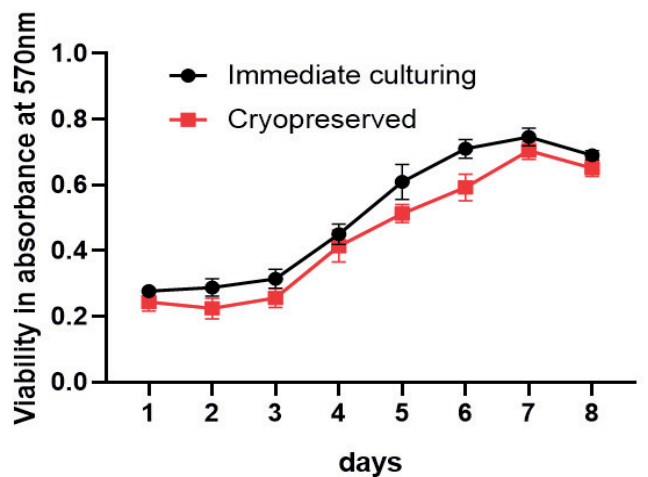

Fig. 3. A. Cells in monolayer in the $2^{\text {nd }}$ passage. No difference in morphology was visible between the immediate culturing group (A-I, III) and cryopreserved group (A-II, IV). B. Growth curve of cells from the 10 pairs of immediate culturing/cryopreserved pulp tissue fragments (in mean and standard deviation).

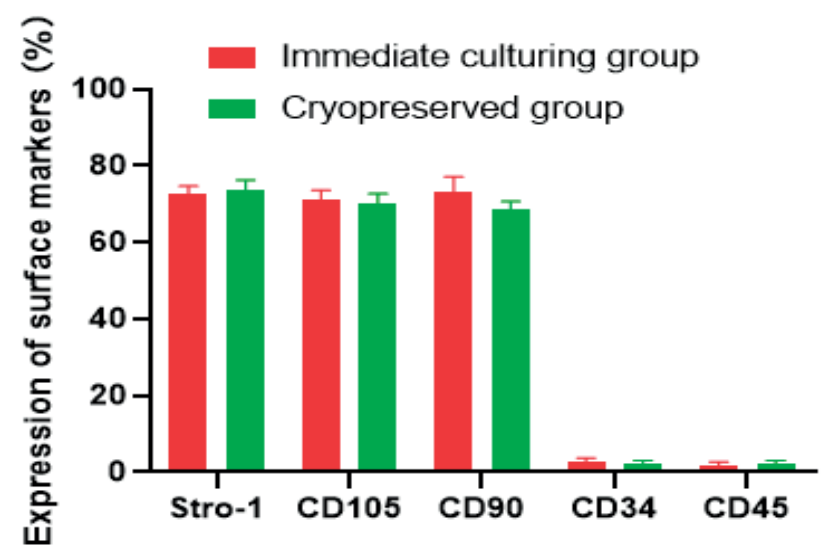

Fig. 4. Nearly identical expression of stem cell markers in cells from the paired immediate culturing/cryopreserved pulp tissue fragments. then slowly transferred to a culture dish with $15 \mathrm{~mL}$ prewarmed medium. Fresh pulp tissue fragments without cryopreservation was used for culturing cells in the same way (Fig. 1). The medium was changed on the next day. Then the dishes were kept in the incubator for two days. It was important not to move the dishes during these first two days to enable the pulp tissue explants to attach to the culture surface. From day 3, the dishes were checked daily under a microscope to follow the outgrowth of the cells from the explants. The day for first cell outgrowth was recorded. By confluence of $70-80 \%$, the cells in monolayer were harvested with $0.125 \%$ trypsin, counted and passaged.

\section{Characterization of the pulp cells}

Cell viability was measured using a MTS assay (Promega) following the instruction of the supplier.

Cells in passage 3 were used for labelling with antibodies for surface markers of cells including STRO-1 (cat. no. 14-6688-82; thermo Fisher Scientific, Inc.), CD105 (cat. no. ab156756; Abcam), CD90 (cat. no. ab139364; Abcam), CD34 (cat. no. 560941; BD Biosciences) and CD45 (cat. no. MCA2035S; Bio-Rad Laboratories, Inc), all diluted at 1:500. The cell suspension was adjusted to a density of $1 \times 10^{9} / \mathrm{L}$ and passed through a $70 \mu \mathrm{m}$ filter. After $30 \mathrm{~min}$ incubation at $4^{\circ} \mathrm{C}$ in darkness, the labelled cells were analyzed on a flow-cytometry device.

\section{Differentiation}

Cells in the $3^{\text {rd }}$ passage were seeded at a density of $8 \times 10^{3} / \mathrm{mL}$ and grew to $70-80 \%$ confluence. Then the media were changed to adipogenic (with additives of $10 \mathrm{mg} / \mathrm{mL}$ insulin, $0.5 \mathrm{mM}$ methylxanthine, $1 \mathrm{mM}$ dexamethasone, $0.1 \mathrm{mM}$ indomethacin) or osteogenic (with additives of $10 \mathrm{mM} \beta$-glycerophosphate, $0.05 \mathrm{mM}$ vitamin C, $0.1 \mathrm{mM}$ dexamethasone) inducing media and the differentiation was continued for 3 weeks. At the end of the differentiation, the cells were stained with $0.5 \%$ oil red $\mathrm{O}$ (Sigma-Aldrich, Saint Louis, MI, USA cat no 00625) or 2\% Alizarin red S (Sigma-Aldrich, Saint Louis, MI, USA cat. no. 130-22-3) to visualize oil droplets in adipose cells and mineral sediments produced in osteoblasts, respectively. To quantify lipid droplets, the oil red $\mathrm{O}$ in each well was dissolved in $500 \mu \mathrm{L}$ isopropanol and the absorption was read at $540 \mathrm{~nm}$. Quantitative analysis of osteogenic differentiation was carried out by dissolving Alizarin red $\mathrm{S}$ in $500 \mu \mathrm{L}$ of $10 \%$ acetic acid and a subsequent neutralization with an equal volume of $10 \%$ ammonium hydroxide. The absorbance value was read at $405 \mathrm{~nm}$.

\section{RESULTS}

\section{Cell outgrowth and proliferation}

For all the 10 cryopreserved dental pulp tissue fragments included in this study, the time to cell outgrowth (vital cells migrated from the tissues) was around 7 days. In the immediate culturing group, the cell was grown out from the tissue at day 5 whereas it was on day 7 in the 
A
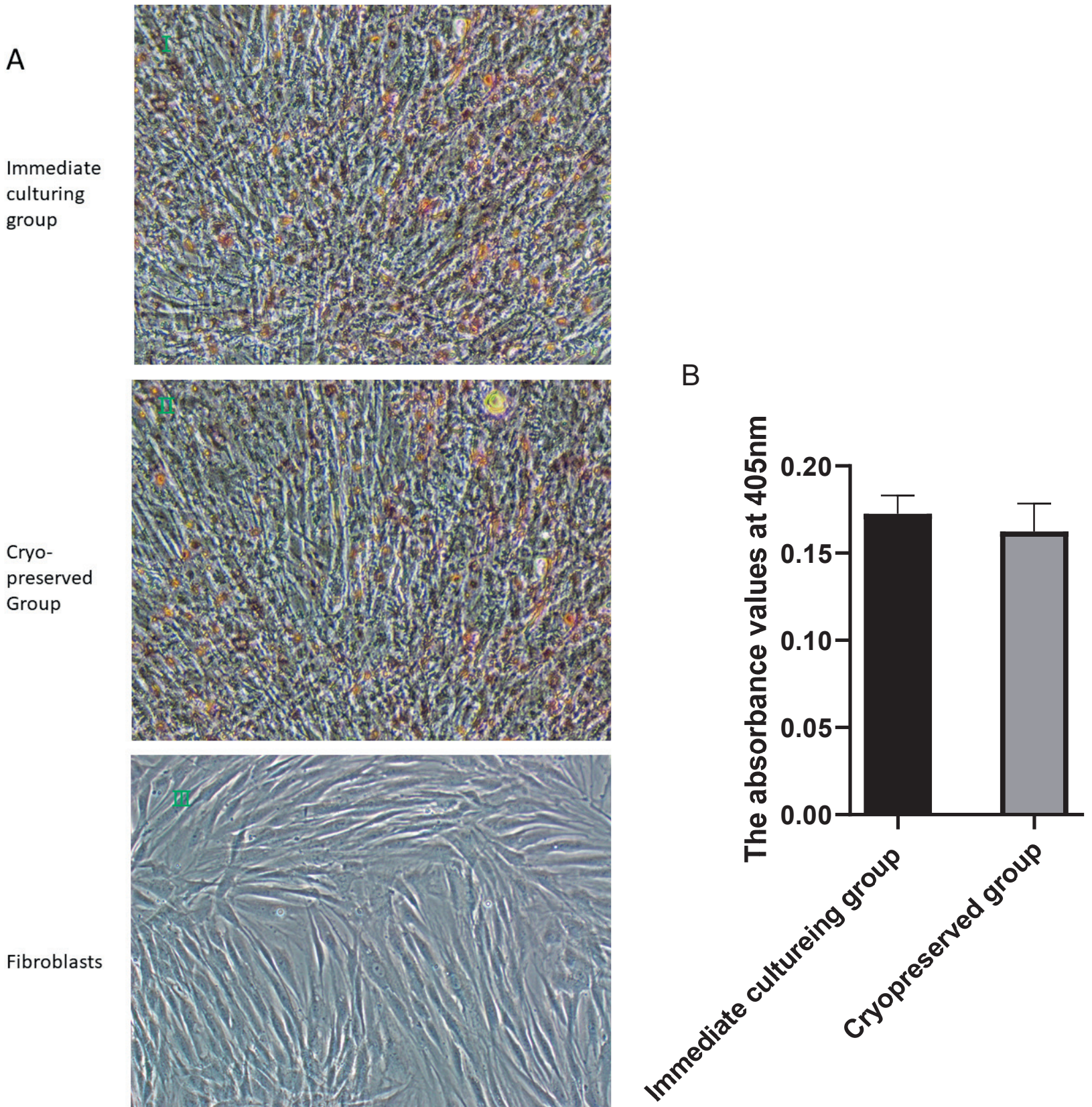

Fig. 5. A. Osteogenic differentiation of cells from paired immediate culturing/cryopreserved pulp fragments. Mineral sediments stained with Alzerin were clearly visible. Human gingival fibroblasts in primary culture were included as a negative control. B. quantiviation of dissolved alzerin did not detect significant difference between the immediate culturing/cryopreserved group $(P>0.05)$.

cryopreserved group. (Fig. 2A). The mean time to cell outgrowth in immediate culturing group was significantly shorter than the cryopreserved group $(P<0.05)$. For fresh pulp tissues, cell outgrowth was approximately 2-day earlier (Fig. 2B). However, once the cells migrated out and grew in monolayer, the same spindle, triangle and long spindle morphologies were observed for tissue fragments with and without cryopreservation (Fig. 3A). Also the growth curves of the cells from the two groups of tissue fragments were comparable (Fig. 3B).

\section{Expression of stem cell markers}

Pulps are made up of mesenchymal stem cells most$1 \mathrm{y}^{10}$, and markers that are more consistently reported are STRO-1, CD73, CD90, CD105, CD146, Oct4, Nanog, beta2 integrin positive, and CD14, CD34, CD45, and HLA-DR negative expression in mesenchymal stem cells $^{11-13}$. In our study, flow cytometry analysis revealed compatible expression of 5 markers [(Stro-1, CD105, CD90 are positive), (CD45, CD34 are negative)] in cells from the pulp tissue fragments with and without cryopreservation. In both groups, approximately $70 \%$ of the cells were positive for Stro-1, CD105 and CD90. However, less than $10 \%$ of the cells were positive for CD34 and CD45 (Fig. 4).

\section{Multipotential in differentiation}

Dental pulp cells all exhibited the potential of adipogenic and osteogenic differentiation regardless of cryopreservation. Mineral sediment in cells under osteogenic 

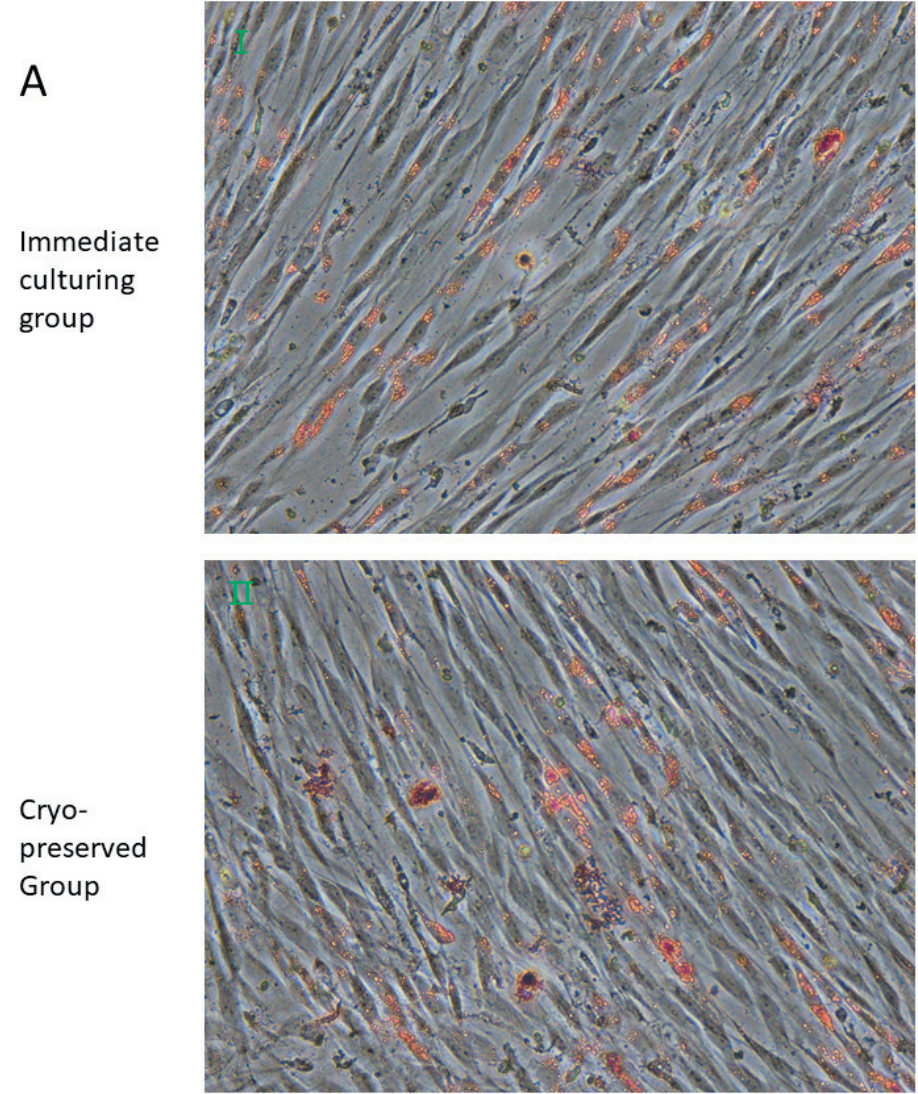

Fibroblasts

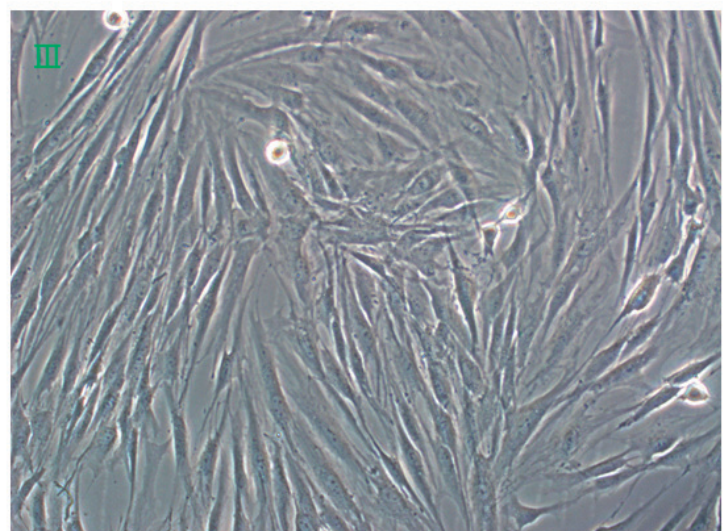

B

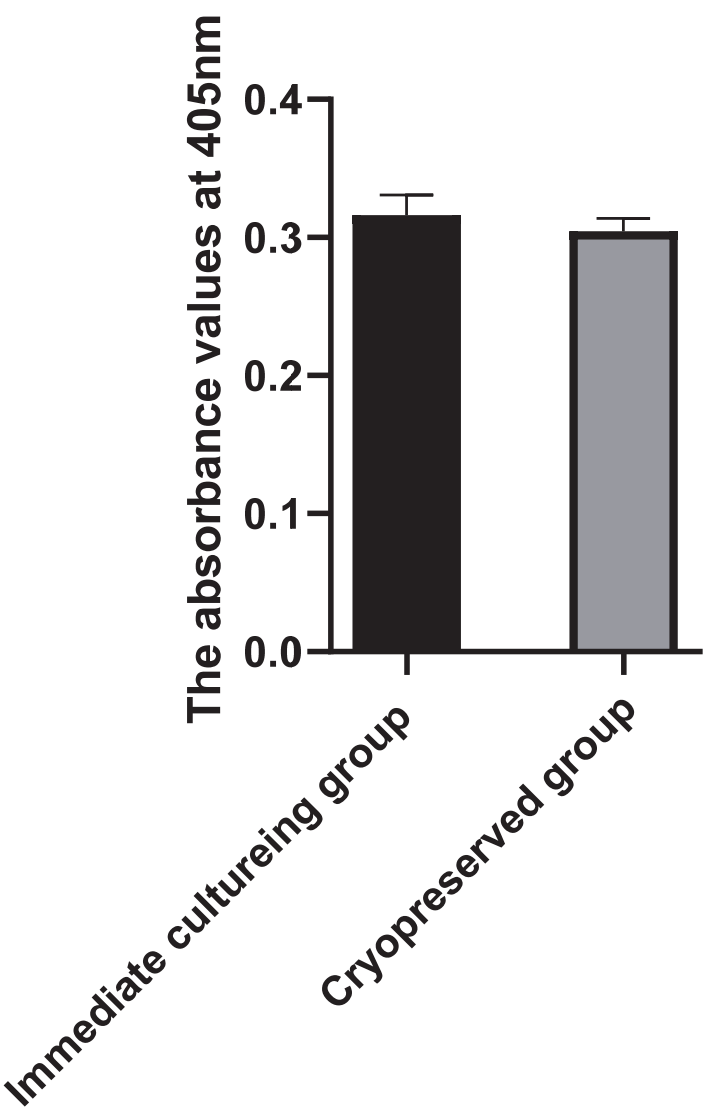

Fig. 6A. Adipogenic differentiation of cells from paired immediate culturing/cryopreserved pulp tissue fragments. Oil droplets stained with $0.5 \%$ Oil red $\mathrm{O}$ were visible in red-orange color. Human gingival fibroblasts in primary culture were included as a negative control. B. quantification of Oil red $\mathrm{O}$ did not revealed significant difference between the immediate culturing/cryopreserved group $(P>0.05)$.

induction (Fig. 5) and oil-droplets in cells under adipogenic induction were clearly visible (Fig. 6). No difference was visible between the two groups of cells cultured using the fresh and cryopreserved tissue fragments. By contrast, no oil droplets nor mineral sediments were seen in the control primary gingival fibroblasts under the same inducing conditions, suggesting that the differentiation is a specific feature of the pulp cells, again, regardless of cryopreservation (Fig. 5A, 6A).

\section{DISCUSSION}

The choice of optimal seed cells is crucial during tissue engineering. Pulp cells which are one of the most studied stem cells, meet the rigorous criteria of an ideal source of seed cells for use in tissue engineering and cell therapy ${ }^{14,15}$. In pulp cell culture, the liquid nitrogen cryopreservation method is used as a standard method to store and bank ${ }^{16,17}$. Furthermore, methods have been updated continuously with the developments inbiotechnology ${ }^{18,19}$. The viability and differentiation capacity of dental pulp stem cells have been reported after two years of cryopreservation ${ }^{20}$. For the pulp tissue cryopreservation, Perry et al. showed that the tissues can be recovered from cryopreserved intact tooth at $4{ }^{\circ} \mathrm{C}$ refrigerator for up to 5 days $^{21}$. In order to solve this problem, long-term cryopreserved dental pulp tissues, in our study, we demonstrated the feasibility of cryopreserving human dental pulp tissue fragments from which vital cells can be cultured later for long-term cryo- 
preservation using our method. The cells cultured from the cryopreserved tissue fragments exhibited compatible proliferation and differentiation potential as cells cultured from their fresh counterparts. The difference between the two groups was the two-days delay in cell-outgrowth for the cryopreserved explants. This result is consistent with those of previous research that the growth of primary pulp cells requires an adaptation period after long-term cryopreservation $^{22}$.

Since the cultures are still in their 3-5 passages, we do not have the data at present for the total yield of cells. However, we expect that some cells will be damaged in the cryopreservation process and consequently, the total yield will not be as good as in the case of fresh tissues. Further studies need to address this issue.

A possible explanation for our success in obtaining vital cells from the cryopreserved pulp tissue fragments may be the loose packing structure of the pulp cells in the pulp tissue which allows sufficient penetration of the cryoprotecting agent DMSO as in the case of a single cell suspension. The other possible reason may be associated with the small volume of sample $\left(<0.5 \mathrm{~cm}^{3}\right)$. As highlighted above, we propose minimizing the fragments volume as much as possible. For other tissues, this strategy may not be feasible. In the present study, our aim was to obtain single cells for culture. Therefore, it was not essential to maintain the original structure and cell organization of the tissue. However, the structure and cell organization may have been altered in the cryopreservation process and that may one reason for the delayed cell outgrowth from the one cryopreserved explants.

Despite the slightly delayed outgrowth, once vital cells were obtained from cryopreserved tissue fragments, similar features were expected for them as for the cells from fresh tissue fragments. We indeed observed compatible features in the paired fresh/cryopreserved tissue fragments as regarding proliferation, and adipogenic and osteogenic differentiation. Importantly, such differentiation was completely absent in the fibroblasts which were included as a negative control under the identical differentiation conditions, providing strong supporting evidence that the observed differentiation is specific for the human dental pulp cells. Our results are in agreement with published reports that cryopreservation does not cause changes in biological characteristics, structural, mechanical or biological properties ${ }^{23}$.

Since the primary aim of the present study was to test the feasibility of cryopreservation of fragmented pulp tissues for later culturing vital cells, cutting the pulp tissues into fragments were carried out in the laboratory on a sterile culture bench to prevent contamination. In an ongoing study, we are testing the feasibility of preparing pulp tissues under standard clinical setting without a laboratory sterile bench. Should at least some of the pulp tissues survive the potential infection, preservation will be feasible at teeth extraction in any dental or oral clinic. The only necessary device is a home-hold $-20^{\circ} \mathrm{C}$ freezer for temporary storage of tissue fragments which can be transported to a $-80^{\circ} \mathrm{C}$ freezer later at any time of convenience and finally into the liquid nitrogen for long term preservation.

\section{CONCLUSION}

In summary, our study demonstrated that vital cells can be cultured from cryopreserved dental pulp tissue when cut into small fragments. Proliferation and differentiation potentials of these cells were sustained. Using this strategy, substantially more patients will have the option of saving their pulp tissues as an autologous cell sources for possible later application.

\section{ABBREVIATIONS}

DMSO, dimethylsulfoxide; CD105, Endoglin; CD90, Cluster differentiation 90/Thy-1 antigen; CD34, Hematopoietic progenitor cell antigen 1, and CD45, Leukocyte common antigen.

Ethics approval and consent to participate: Administrative permissions were acquired by our team to access the data used in our research. The study protocol was approved by the University Medical Center Hamburg-Eppendorf that approved the study. Accordingly, all teeth were coded with a number and all personal identification of the patients was removed. All parent or guardians of participants provided written informed consent for using the teeth which otherwise would have been discarded as waste.

Author contributions: MY: conceived the study, supervised the experiments and drafted the manuscript; RF: designed the experiments and drafted the manuscript; ON: data evaluation, medical writing and editorial assistance in preparing this manuscript for publication; RS: performed the data collection; MG: analyzed the data and revised the manuscript; LK: conceived the study together with All authors have read and approved the manuscript.

Conflict of interest statement: The authors state that there are no related conflicts of interest.

\section{REFERENCES}

1. Gronthos S, Mankani M, Brahim J, Robey PG, Shi S. Postnatal human dental pulp stem cells (DPSCs) in vitro and in vivo. Proc Natl Acad Sci U S A 2000;97(25):13625-30.

2. Aydin S, Sahin F. Stem Cells Derived from Dental Tissues. Adv Exp Med Biol 2019;1144:123-32.

3. Dehghani Nazhvani A, Ahzan S, Hosseini SM, Attar A, Monabati A, Tavangar MS. Purification of Stem Cells from Oral Pyogenic Granuloma Tissue. Open Dent J 2018;12:560-66.

4. Wang Z, Pan J, Wright JT, Bencharit S, Zhang S, Everett ET, Teixeira FB, Preisser JS. Putative stem cells in human dental pulp with irreversible pulpitis: an exploratory study. J Endod 2017;36(5):820-25.

5. Chalisserry EP, Nam SY, Park SH, Anil S. Therapeutic potential of dental stem cells. J Tissue Eng 2017;8:2041731417702531.

6. Young F, Sloan A, Song B. Dental pulp stem cells and their potential roles in central nervous system regeneration and repair. J Neurosci Res 2013;91(11):1383-93.

7. Fabricant L, Kiraly L, Wiles C, Differding J, Underwood S, Deloughery T, Schreiber M. Cryopreserved deglycerolized blood is safe and 
achieves superior tissue oxygenation compared with refrigerated red blood cells: a prospective randomized pilot study. J Trauma Acute Care Surg 2013;74(2):371-76; discussion 376-377.

8. Xu X, Cowley S, Flaim CJ, James W, Seymour LW, Cui Z. Enhancement of cell recovery for dissociated human embryonic stem cells after cryopreservation. Biotechnol Prog 2010;26(3):781-88.

9. Zanata F, Bowles A, Frazier T, Curley J, Bunnell BA, Wu X, Wade J, Devireddy R, Gimble JM, Ferreira LM. Effect of Cryopreservation on Human Adipose Tissue and Isolated Stromal Vascular Fraction Cells: In Vitro and In Vivo Analyses. Plast Reconstr Surg 2018;141(2):232e$243 e$.

10. Gronthos S, Brahim J, Li W, Fisher LW, Cherman N, Boyde A, DenBesten P, Gehron R, Shi S. Stem cell properties of human dental pulp stem cells. J Dent Res 2002;81(8):531-35.

11. Gronthos S, Zannettino AC, Hay SJ, Shi S, Graves SE, Kortesidis A Simmons PJ. Molecular and cellular characterisation of highly purified stromal stem cells derived from human bone marrow. J Cell Sci 2003;116(Pt 9):1827-35.

12. Gu K, Smoke RH, Rutherford RB. Expression of genes for bone morphogenetic proteins and receptors in human dental pulp. Arch Ora Biol 1996;41(10):919-23.

13. Kerkis I, Kerkis A, Dozortsev D, Stukart-Parsons GC, Massironi SM, Pereira LV, Caplan Al, Cerruti HF. Isolation and characterization of a population of immature dental pulp stem cells expressing OCT4 and other embryonic stem cell markers. Cells Tissues Organs 2006;184(3-4):105-16.

14. Miura M, Gronthos S, Zhao M. SHED: stem cells from human exfoliated deciduous teeth. Proc Natl Acad Sci U S A 2003;100(10):580712.
15. Alongi DJ, Yamaza T, Song Y, Fouad AF, Romberg EE, Shi S, Tuan RS, Huang GT. Stem/progenitor cells from inflamed human dental pulp retain tissue regeneration potential. Regen Med 2010;5(4):617-31.

16. Thirumala S, Goebel WS, Woods EJ. Clinical grade adult stem cell banking. Organogenesis 2009;5(3):143-54.

17. Munevar JC, Gutierrez N, Jimenez NT, Lafaurie GI. Evaluation of two human dental pulp stem cell cryopreservation methods. Acta Odontol Latinoam 2015;28(2):114-21.

18. Takebe Y, Tatehara S, Fukushima T, Tokuyama-Toda R, Yasuhara R, Mishima K, Satomura K. Cryopreservation Method for the Effective Collection of Dental Pulp Stem Cells. Tissue Eng Part C Methods 2017;23(5):251-61.

19. Huynh NC, Le SH, Doan VN, Ngo LTQ, Tran HLB. Simplified conditions for storing and cryopreservation of dental pulp stem cells. Arch Oral Biol 2017;84:74-81.

20. Alsulaimani RS, Ajlan SA, Aldahmash AM, Alnabaheen MS, Ashri NY. Isolation of dental pulp stem cells from a single donor and characterization of their ability to differentiate after 2 years of cryopreservation. Saudi Med J 2016;37(5):551-60.

21. Perry BC, Zhou D, Wu X, Yang F, Byers MA, Chu TG, Hockema JJ, Woods EJ, Goebel WS. Collection, cryopreservation, and characterization of human dental pulp-derived mesenchymal stem cells for banking and clinical use. Tissue Eng Part C Methods 2008;14(2):14956.

22. Collart Dutilleul PY, Thonat C, Jacquemart $P$, Cuisinier $F$, Levallois $B$ Chaubron F. Dental pulp stem cells: characteristics, cryopreservation and therapeutic potentialities. Orthod Fr 2012;83(3):209-16.

23. Balci D, Can A. The assessment of cryopreservation conditions for human umbilical cord stroma-derived mesenchymal stem cells towards a potential use for stem cell banking. Curr Stem Cell Res Ther 2013;8(1):60-72. 